\title{
Analysis of the Relationship between the Distance from Urban Open Spaces and Citizens' Accessibility and Usage
}

\author{
Amir Hamzeh Shahbazi (Corresponding Author) \\ Ph.D. student of geography and urban planning \\ Department of Geography and urban Planning, Faculty of Geographical Sciences \\ University of Isfahan, Isfahan, Iran \\ Tel: 98-54-1244-3385Ｅ-mail: amir_3_1285@yahoo.com \\ Asghar Zarabi \\ Professor of Geography and Urban Planning University of Isfahan, Isfahan, Iran \\ Department of Geography and Urban Planning, University of Isfahan, Isfahan, Iran \\ Tel: 98-31-1793-3160_E-mail: aszarrabi@yahoo.com \\ Masood Taghvaei \\ Professor of Geography and Urban Planning University of Isfahan, Isfahan, Iran \\ Department of Geography and Urban Planning, University of Isfahan, Isfahan, Iran \\ Tel: 98-31-1793-3160Ｅ-mail: m.taghvaei@1tr.ui.ac.ir
}

Received: October 22, 2013 Accepted: November 4, 2013

doi:10.5296/emsd.v3i1.4439 URL: http://dx.doi.org/10.5296/emsd.v3i1.4439

\begin{abstract}
The current study, aims at analyzing the relationship between the distance from urban open spaces and citizens' access to and usage of those spaces. The necessity of this study roots in modern life damages including increasing urbanization, separation from nature, individualism and decrease in face-to-face social interaction, ever-increasing stress and decrease in people's power and tolerance. Therefore, regarding negative consequences on people' bodies and souls, the importance of urban open spaces has been highlighted. Research method is survey. For data gathering, researcher-made questionnaires have been used. Based on data type which has nominal and ordinal measurement scales, Chi-square and Kruskal Wallis Models have been employed. Also, the present research is applied and problem-oriented. Research population consists of Isfahan citizens and research sample has been selected through random sampling. Research hypothesis is "the extent citizens use urban open spaces (meaning that
\end{abstract}


neighborhood parks). The Sample size was equal 366 respondents (valid questionnaires=366). The independent variable is, the distance of citizens from those spaces". Findings indicate that there is a significant relationship between distance of citizens' housings from urban open spaces as independent variable and their usage from those spaces as dependent variable. This relationship's significance level is 0.05 with 4 degree of freedom. In addition, with significance level of 0.01 , there is significant relationship between settlement in different neighborhood and the attitude of citizens toward the distance from neighborhood parks as a barrier on the way of going to parks. Therefore, the conclusion emphasizes, on build more parks and of course closer to citizens, for reduces distance to parks. Otherwise, it's obviously the physical and psychological damage will occur

Keywords: Urban Open Spaces, Neighborhood Park, accessibility, Green Spaces, Isfahan.

\section{Introduction}

\subsection{The Importance and Necessity of Current Research}

Lack of proper urban open spaces, especially in neighborhoods, Insufficient access to urban open spaces for citizens, with regarding to improper distribution of urban open spaces have been caused mental and physical damages in urban centers. Health damages resulted from lack of physical activities such as overweight, cardiovascular problems, Sociological damages Include disorder in social interaction, socialization and face-to-face social interactions.

These are part of the reasons that this survey was conducted. Considering that the Isfahan is one of the metropolitans. Survey conducted to test the hypothesized relationship between the variables walking distance to the park and use of the park.

\subsection{Research Goals}

Analysis of the effect of citizens' distance from Urban opens spaces and their usages of those spaces. Analysis the relationship between Neighborhoods locality and their settlers 'attitudes about the functions of urban open spaces. Analysis relationship between use of Neighborhood Park and their general mental status (based on their opinion)

\subsection{Research Hypothesis}

There is significant relationship between distance from urban open spaces and the citizen's use of those spaces.

There is significant relationship between going and using of Neighborhood Park and general mental status

There is significant relationship between use of urban open spaces and citizens mental status.

\section{Research Literature}

Lee (2011) found and shows the decelerating trend in physical activities. There is significant relationship between park usage and people's body mass as well as blood pressure conditions. According to Walker et al (2009), it is Beneficial for stressful people to know about 
usefulness of parks. Two basic theories have been discussed on: a) ART (Attention Restoration Theory) by Kaplan (2001) and b) Pet (Psycho-evolutionary Theory) by Ulrich, et al (1991).

Hwa Shin (2011) attempts to investigate and evaluate the effects of environmental factors on the extent of physical activities of elderly African females, 55 to 85 years old, living in Brian City of Texas State, USA. Findings indicate that there positive significant relationship between the distance from open spaces and the extent of physical activities among research sample.

Tanes (2010 has tested a hypothesis on the effects of virtual space on the perception changes in Turk adolescents. They found that virtual spaces affected expectations from users' behavioral patterns.

Schipperijn (2010) has surveyed factors effective on green space usage in a Danish national representative survey. $70 \%$ of respondents have distances to 300 meters from green spaces; $43 \%$ of respondents in a daily basis and $92 \%$ in a weekly basis have gone to green spaces; only $9 \%$ have never gone to green spaces.

\section{The Importance of Urban Open Spaces and Damages of Inaccessibility to Those Spaces for Citizens}

\subsection{Disability and Early Death}

World Health Organization (WHO) has reported that 5 cases of 10 main reasons of disability and early death have caused by mental conditions worldwide. However, WHO (2004) has predicted that depression will be the main reason of disease among people all over the world till 2025. Also, mental health has been officially recognized as human right which protects people from mental diseases (WHO, 2004). Useful interventions and settings are required for mental health of all people (Maller, et al., 2005)

\subsection{The Priority of Neighborhood Unit for Public Open Space}

Public open space is one of those settings which has high access in neighborhood level and attracts most of users in different ages, genders and cultural backgrounds and includes parks, recreational areas, sport fields, public regions, costal passages, green lands and fresh and unconstructed lands (Francis et al., 2012).

In previous studies regarding public open space, its consequences on people's physical activities have been investigated (Francis, et al., 2012; Cohen, et al., 2010; Kaczynski, et al., 2009; Ries, et al., 2009).

\subsection{Direct and Indirect Consequences of Public Open Spaces}

Public open space could have direct and indirect consequences on people' spirits (Evans, 2003)

\subsubsection{Direct Consequences of Public Open Spaces}

Direct consequences on health may be through spending leisure times resulted from contact with nature (Herzog, et al., 1997) 


\section{Macrothink \\ Environmental Management and Sustainable Development \\ ISSN 2164-7682 \\ 2014, Vol. 3, No. 1}

\subsubsection{Indirect Consequences of Public Open Spaces}

Indirect consequences on mental health may be through paving for social meetings and socialization (Semenza, 2003)and this trend entails in protecting mental health (Berkman, et al., 2000; Ellis, 2006).

\subsubsection{Dependence of Land Use on Quality of Public Spaces}

According to Francis and his colleagues (2012), low quality spaces are compatible with such activities as walking with dog and high quality spaces with some kinds of recreational choices and social activities because people need to stop, sit, stand, eat, and play etc in such places (Gehl, 2006: 11).

\subsubsection{Index of Quality of Open Public Spaces}

This index consists of the ten weighted indexes selected by a board of experts and those indexes include pedestrian Pathways, shadow, irrigated grasses, bird life, light, sport facilities, play grounds, road type around and water presence near to or in neighborhood of the land (Giles-Corti, et al., 2005).

\section{Survey Findings}

Regarding to the identified hypothesis, it's time for testing the hypothesis. According to data obtained from questionnaire and specially data scale that are from ordinal type, tis necessary to apply the Chi-square\& Kruskal Wallis Tests. The important point in this survey is to test and evaluate any relationship between dependent variable (going and usage of Neighborhood parks, or importance of distance, or respondent's general mentality) and some of independent variables (such as distance to Neighborhood parks, or status of Neighborhoods locality.

\subsection{The First Main Hypothesis: about distance and Accessibility}

There is significant relationship between physical characteristics of urban open spaces (distance from citizens' settlements) and the extent citizens use those spaces.

First Sub-hypothesis:

HA: the extent citizens go to and use neighborhood parks depends on the distance of those spaces and citizens' housings.

H0: There is no relationship between the extent citizens use neighborhood parks and the distance of those spaces and citizens' housings (null hypothesis or no difference).

Independent variable X: distance of Neighborhood Park from housing----scale: Ordinal Dependent variable Y: extent of going to and using neighborhood park---- scale: Ordinal Statistical method for testing: Chi Square - Kruskal Wallis

Test result: According to data obtained from field study as well as Chi Square - Kruskal Wallis methods, significance level is 0.05 between dependent and independent variables. 


\section{Ml Macrothink}

Environmental Management and Sustainable Development

ISSN 2164-7682 2014, Vol. 3, No. 1

Table 1. Relationship between extent of going to and using small neighborhood park and distance of Neighborhood Park from housing

\begin{tabular}{|c|cc||}
\hline \multicolumn{2}{|l|}{ Test Statistics $^{\mathrm{a}, \mathrm{b}}$} \\
\hline \hline Dependent variable & going to and using neighborhood park \\
\hline Chi-square & 9.443 \\
\hline $\mathrm{df}$ & 4 \\
\hline Asymp. Sig. & .051 \\
\hline \multicolumn{2}{|c|}{ Kruskal Wallis Test } & sample size(valid questionnaires = 366) $\quad . \mathrm{a}$ \\
\hline \multicolumn{2}{|c|}{ Grouping Variable $:$ distance from neighborhood park $\quad . b$} \\
\hline
\end{tabular}

Reference: Findings from survey study obtained from research questionnaires

Second Sub-hypothesis:

HA: The attitudes of residents of different neighborhood toward their distance from neighborhood parkas as an access barrier is different.

H0: There is no relationship between settling in different neighborhood and the type of attitude toward distance from Neighborhood Park as an access barrier.

Independent variable X: Settling in neighborhoods (14neighborhoods) ---- Scale: nominal

Dependent variable Y: Evaluation of citizens regarding the distance of parks from their houses as barrier for going to parks Scale: ---- ordinal

Statistical method for testing: Chi Square - Kruskal Wallis

Test result: According to statistical findings and results from Chi Square test, in 0.02 levels, this relationship is significant. So, H0 or null hypothesis was rejected, and According to this alternative hypothesis is confirmed.

Therefore, it reveals that in some alleys, distance from parks is considered as access barrier and limits usages of urban open spaces.

Table 2. Relationship between where people settle and their distance from parks as access barrier to parks

\begin{tabular}{||c|c||}
\hline \multicolumn{2}{|l||}{ Test Statistics $^{\mathbf{a}, \mathbf{b}}$} \\
\hline \hline Dependent variable & Distance from neighborhood park \\
\hline \hline Chi-square & 102.439 \\
\hline df & 11 \\
\hline Asymp. Sig. & .000 \\
\hline \hline a. Kruskal Wallis Test & sample size(valid questionnaires = 366) \\
\hline \hline b. Grouping Variable: neighborhoods locality \\
\hline
\end{tabular}

Reference: Findings from survey study obtained from research questionnaire - 
5.2 The Second Main Hypothesis: about going to Neighborhood park and status of respondents general mentality (on their thought)

HA: Lack of sufficient access to urban open spaces endangers citizens' physical - mental) health.

H0: There is no significance relationship between citizens' mental - physical health and their usages of urban open spaces, and then these variables are independent.

Independent variable X: Going to neighborhood park ---- (Scale: Ordinal)

Independent variable Y: status of general mentality of settlers---- (Scale: Ordinal)

Of course according to their own evaluation

Statistical method for testing: Chi Square- Kruskal Wallis

This hypothesis is tested by Chi-square method; as expected frequencies of $24 \%$ boxes are under 5, to avoid this problem, hypothesis is tested again by Kruskal Wallis and the result showed that its significance level is confirmed in 0.001 level. Findings have been shown in the following table. Test and findings show that there is significance relationship between these two variables.

Table 3. Relationship between extent of going to Neighborhood Park, and respondant's general spirit status.

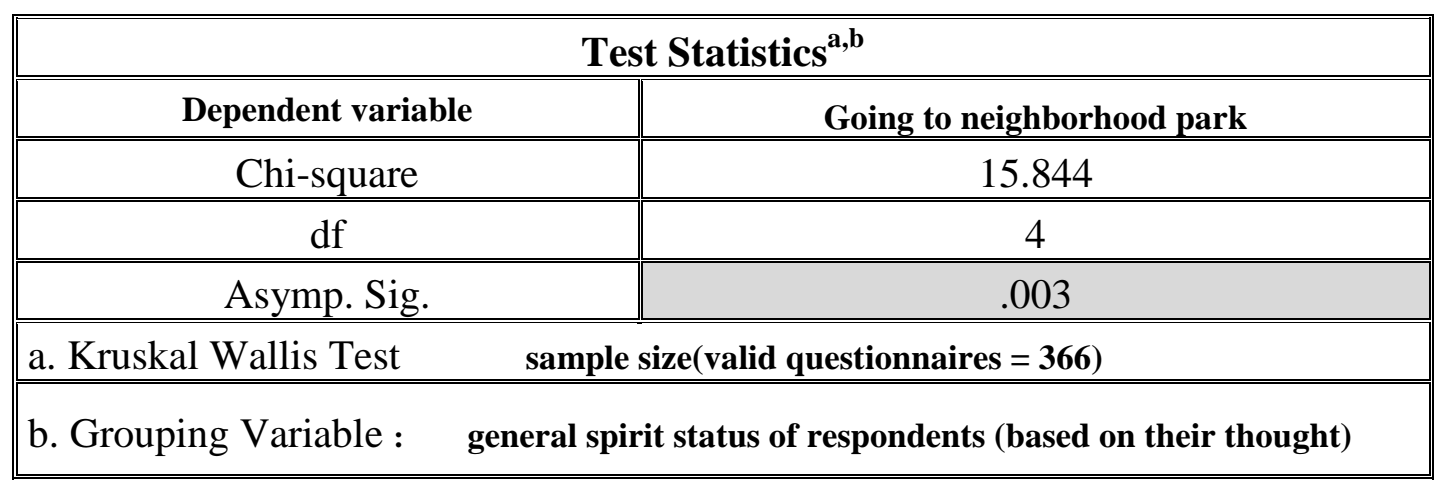

Reference: Findings from field study, obtained from research questionnaire.

Findings shown that respondent's general mentality is associated with Going to Neighborhood Park, and also going to Neighborhood Park Is associated with Distance from Neighborhood Park, and so Distance from Neighborhood Park Is associated with Neighborhoods locality status.

\section{Conclusions}

According to theoretical findings, partly mentioned in research literature, indexes which differentiate modern world from traditional one include urbanization, farness of men from nature, Automation and decrease in human physical activities, ever-increasing phenomenon of stress in daily life and its resulted mental fatigue, individualism and decrease in social 
affiliations. Therefore, it is expected that urban managers pave for controlling and restricting damages resulted from above-mentioned factors through providing public urban open spaces, parks. Those measures should be taken may include access to natural green spaces such as neighborhood parks, or district parks for leisure time and mental relaxation for better life, more social interaction for social unity and transition of social and civil values. Lack of before-mentioned phenomena has mad modern communities vulnerable.

As Kruskal Wallis statistic model has shown, in research population, there is basically significant relationship between distance of citizens' housings from urban open spaces as independent variable and their usage from those spaces for spending leisure times, sporting activity and physical exercises and promenade as well as sitting and talking as dependent variable. This finding obviously puts emphasis on the importance of planning, investing in, constructing and controlling safety and welfare of urban open spaces, especially in neighborhood level. It is clear that this finding, in line with internationally carried out studies, accentuates reduction of distance for encouraging and promoting usages of urban parks.

However, although high amount of urban open spaces and green spaces may show urban ecological capacity and capability, their improper distribution entails in lack of access of some citizens to those spaces. As hypothesis test has shown, urban different Neighborhood has given different, but significant responses to this question: to what extent could the distance from urban open spaces prevent your access to those spaces? Combining data obtained from questionnaires and field observations confirms research main hypothesis. Therefore, proper spatial distribution of those spaces and avoidance from much reliance on general urban indexes are so important.

With great emphasis, the current research calls for detailed research of leisure time issues, exploitation of media and internet facilities issues and the manner citizens evaluate how to use open spaces as well as usage barriers of urban spaces.

Based on the results of the data obtained from questionnaires, And Findings from testing search hypotheses offers the following comments: If managers and urban planners want to have citizens with healthy and happy mood, it is necessary to have a sufficient attention in urban open spaces. So they can have access with a short distance to the park and urban open space.

\section{References}

Berkman, L. F., Glass,T., Brissette, I., \& Seeman, T. E. (2000). From social integration to health: Durkheim in the new millennium. Social Science \& Medicine, 51, 843-857. http://dx.doi.org/10.1016/S0277-9536(00)00065-4

Cohen, D. A., Marsh, T., Williamson, S., Derose, K. P., Martinez, H., Setodji, C., McKenzie, T. L. (2010). Parks and physical activity: why are some parks used more than others?. Preventive Medicine, 50, S9-S12. http://dx.doi.org/10.1016/j.ypmed.2009.08.020. 
Cohen, D. A., Marsh, T., Williamson, S., Derose, K. P., Martinez, H., Setodji, C., et al. (2013). Exploring Park Director Roles in Promoting Community Physical Activity. http://www.ncbi.nlm.nih.gov/pmc/articles/PMC3756688/

Ellis, J. A. (2006). Social ties and health. American Journal of Health, 96(8), 1341. http://dx.doi.org/10.2105/AJPH.2006.093633

Evans, G. W. (2003). The built environment and mental health. Journal of Urban Health, 80(4), 536-555. http://dx.doi.org/10.1093/jurban/jtg063

Gehl, J. (1987/2011). Life between buildings, using public space, Skive, The Danish Architectural Press. http://joss.bartlett.ucl.ac.uk/journal/index.php/joss/article/download/104/pdf

Giles-Corti, B., Broomhall, M.H., Knuiman, M., Collins, C., Douglas, K., Ng, K., Lange, A., Donovan, R. J. (2005). Increasing walking: how important is distance to attractiveness and size of public open space?. American Journal of Preventive Medicine, 28(2, Suppl. 2), 169-176. http://dx.doi.org/10.1016/j.amepre.2004.10.018

Kaczynski, A. T., Potwarka, L. R., Smale, B. J. A., \& Havitz, M. E. (2009). Association of Parkland proximity with neighborhood and park-based physical activity: variations by gender and age. Leisure Sciences: An Interdisciplinary Journal, 31(2), 174-191. http://dx.doi.org/10.1080/01490400802686045

Kaplan, S. (2001). Meditation, Restoration, and the Management of Mental Fatigue $\begin{array}{llll}\text { Environment and 33(4). } & \text { Behavior, }\end{array}$ http://www.nrs.fs.fed.us/pubs/jrnl/2001/nc_2001_kaplan_005.pdf

Lee, K. (2011). The Role of Outdoor Recreation in Promoting Human Health, Illuminare: A Student Journal in Recreation, Parks, and Leisure Studies, 9(1), 47-58.

Maller, C., Townsend, M., Pryor, A., Brown, P., \& St Leger, L. (2005). Healthy nature health people: contact with nature' as an upstream health promotion intervention for populations. Health Promotion International, 21(1), 45-54. http://dx.doi.org/10.1093/heapro/dai03

Ries, A. V., Voorhees, C. C., Roche, K. M., Gittelsohn, J., Yan, A. F., \& Astone, N. M. (2009). A quantitative examination of park characteristics related to park use and physical activity among urban youth. Journal of Adolescent Health, 45(3), S64-S70. http://dx.doi.org/10.1016/j.jadohealth.2009.04.020

Schipperijn,J., Ekholm, O., Stigsdotter, U. K., Toftager, M., Bentsen, P., Jørgensen, F. K., Randrup, T. B. (2010). Factors influencing the use of green space: Results from a Danish national representative survey. Land scape and Urban Planning, 95(3), 130-137. http://dx.doi.org/10.1016/j.landurbplan.2009.12.010

Semenza, J. (2003). The intersection of urban planning, art, and public health: the Sunnyside piazza. American Journal of Public Health, 93(9), 1439-1441. http://www.ncbi.nlm.nih.gov/pmc/articles/PMC1447989/ 


\section{Macrothink}

Environmental Management and Sustainable Development

ISSN 2164-7682

Tans, Z., Cemalcilar, Z. (2010). Learning from SimCity: An empirical study of Turkish $\begin{array}{lllll}\text { adolescents. } & \text { Journal } & \text { 731-739 }\end{array}$ http://dx.doi.org/10.1016/j.adolescence.2009.10.007

Thomas, R. H., Andrea, M. B., Kimberlee A. F., Deborah J. K. (1997). Reflection and attentional recovery as distinctive benefits of restorative environments. Journal of Environmental Psychology, 17(2), 165-170. http://dx.doi.org/10.1006/jevp.1997.0051

Ulrich, R. S., Simons, R. F., Losito, B. D., Fiorito, E. Zelson, M. (1991). Stress recovery during exposure to natural and urban environments. Journal of Environmental Psychology, 11(3), 201-230.

W.HO. (2004). Prevention of mental disorders: Effective interventions and policy options. Geneva: World Health Organization. (Summary report)

Woo, H. S., Byoung, S. K., W. Woo, J. S. (2011). The distance effects of environmental Variables on Older African American women's physical activity in Texas. Landscape and Urban Planning, 103(2), 217-229. http://dx.doi.org/10.1016/j.landurbplan.2011.07.011

\section{Copyright Disclaimer}

Copyright reserved by the author(s).

This article is an open-access article distributed under the terms and conditions of the Creative Commons Attribution license (http://creativecommons.org/licenses/by/3.0/). 